\title{
Development of a Design Tool for Sizing and Optimizing Thermosyphon Solar Water Heater Systems: A Case Study for Tripoli-Libya
}

\author{
M.J.R. Abdunnabi ${ }^{* 1}$, D.L. Loveday ${ }^{2}$ and J.A. Wright ${ }^{2}$ \\ ${ }^{1}$ Center for Solar Energy Research and Studies, Tajoura, P.O. Box 12932 Tripoli, Libya \\ ${ }^{2}$ School of Architecture, Building \& Civil Engineering, Loughborough University \\ Loughborough, Leics., LE11 3TU, UK \\ e-mail: ${ }^{1} m_{-} a b d u n n a b i @ c s e r s . l y$
}

\begin{abstract}
Thermosyphon solar water heaters can be considered the most popular solar technology for supplying households with the needed hot water for domestic purposes. However, sizing these systems is mainly based on experience and trial methods, these methods were established more on intuition instead of scientific approaches. This paper is aimed at studying the sizing of thermosyphon systems through the development of a dedicated generic design tool. The tool can be utilized by manufacturers and engineers to arrive at optimized systems designed according to the operating and weather conditions of certain geographical locations. The design tool is implemented in this study to find the optimum system design that fits households in Libya (as a case study in this work) and accounts for the weather conditions of Tripoli and a simple, but representative, hot water load pattern. Two different sizes of thermosyphon systems covers hot water load of 180 lit and 240 lit, and two different configurations with vertical and horizontal tanks are studied and the best fit designs are obtained. The design tool has shown a great potential, and with further development and validation would be capable of widespread commercial application.
\end{abstract}

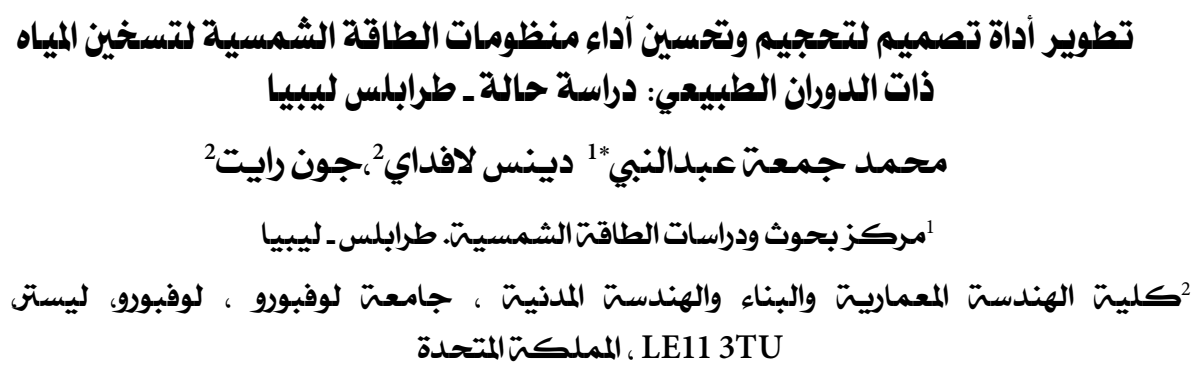

مـلخص: سخانات المياه الشهسيت ذات الدوران الطبيعي تعتبر من أكثر التقنيات الشمسيت شيوعا لتزويد الأسر بمتطلبات المياه

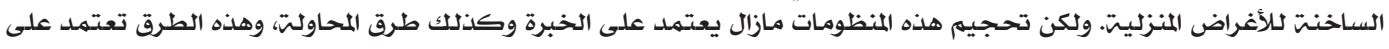




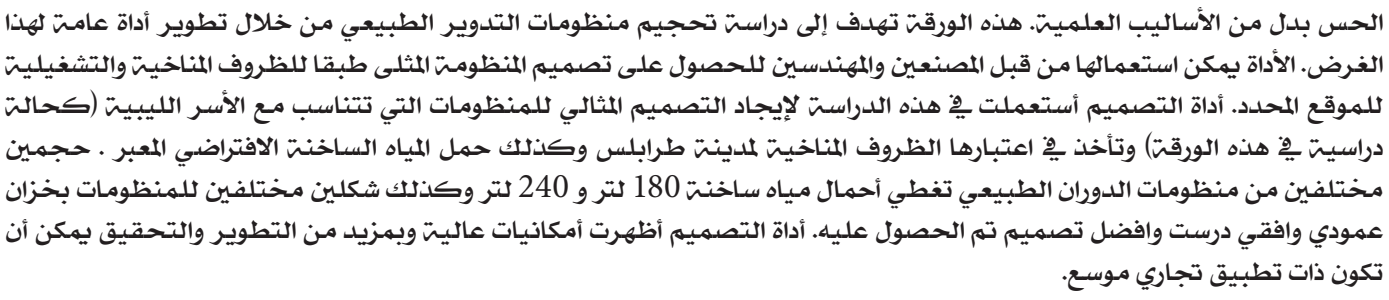

\section{Keywords: Thermosyphon solar water heaters; Genetic algorithm; Optimisation; Design tool.}

\section{INTRODUCTION}

Thermosyphon solar water heating systems are the most commonly used type of solar water heaters for providing households with their hot water requirements for domestic purposes worldwide. Well-designed thermosyphon systems have advantages over other types of systems that include lower investment cost, and reduced operating and maintenance costs. These sorts of systems are particularly suitable for moderate and hot climatic regions where risk of freezing is not an issue.

Designing and sizing of thermosyphon solar water heaters is not an easy task, yet it is very important to produce cost-effectiveness systems, as cost is the main issue that affects the spread of this technology. Literature review has revealed that there are no rigours easy-to-use methods for sizing and optimizing thermosyphon systems, and that most systems available in the market were designed based on trial and error methods which are more based on intuition rather than scientific methods [1]. This can be attributed to the fact that modeling the thermosyphon phenomenon in these systems is a very complicated task.

Most of the previous work regarding optimization of the design variables of domestic thermosyphon solar water heaters have applied the single variable optimization method (or parametric study) in their analyses [2-4]. This is conducted by fixing all variables, and then varying only one variable at a time to see its effect. Strictly, such a method cannot really represent accurately the problem under investigation since the number of variables is large and the problem inherently is multi-objective.

A great deal of work [5-9] has been published regarding sizing and optimizing of active solar water heaters, and of thermosyphon systems [10-16] based on classical optimization techniques. However, some work has been devoted to the use of evolutionary algorithms to optimize large scale solar water heaters utilized in industrial or service applications. Loomans and Visser [17] used a genetic algorithm to minimize the payback time of a large scale solar domestic hot water heating system.

Hin and Zmeureanu [18] utilised a Hybrid Particle Swarm and a Hooke-Jeeves generalized pattern search algorithm to optimize solar combisystem in a house in Montreal, Canada. The objective function used was to minimize the life cycle cost, energy use and exergy destroyed by the system. The optimization results show a reduction in life cycle cost of the combisystem of $19 \%$ and in the life cycle energy use of $34 \%$. Rey and Zmeureanu [19] have used two different methods of optimisation: weighted sum method (WSM) using a hybrid particle swarm optimization/Hooke-Jeeves algorithm (PSO/HJ), and multi-objective particle swarm optimization for the optimisation of a solar combisystem (MOPSO). Also hybrid (MOPSO/HJ) is proposed to enhance the local search of MOPSO. Two conflicting objective functions, the life cycle cost and life cycle energy are used in the optimisation. The results have shown that the proposed MOPSO/HJ is six times faster than WSM in arriving at the solution, and the life cycle cost and life cycle energy were reduced by up to $88.6 \%$ and $63.9 \%$, respectively.

An extensive review of implementing solar water heating systems in TRNSYS is given by Shrivastava et al 
[20]. Nhut and Park [21] have developed a mathematical model to determine the optimal control variables of a collector pump to improve the overall solar water heater performance. The effect of various parameters were investigated under real weather condition of Jeju Island, South Korea. The results have shown that at optimal collector flow rate, the collector useful energy gain is improved by $1.54 \%$ and the electric consumption of the collector pump is decreased to $65.6 \%$. Optimum sizing of solar water heating systems for Libyan households was studied using Generic Optimization Program (GENOPT) provided in TRNSYS by Abdunnabi [22]. The study has shown that the optimum tank volume to collector ratio is between $49-60 \mathrm{Litres} / \mathrm{m}^{2}$ for the most common collector characteristics ratio $\left(\mathrm{F}_{\mathrm{R}} \mathrm{U}_{\mathrm{L}} / \mathrm{F}_{\mathrm{R}}(\tau \alpha)=6-8\right)$.

In this paper, a design tool for sizing and optimizing thermosyphon solar water heaters through the use of TRNSYS component Type45 with two new added components, employing an optimization routine based on the genetic algorithm technique. The design tool is used in this study to find the optimum design of thermosyphon solar water that best suits families in Libya.

\section{THERMOSYPHON SYSTEM DESIGN TOOL (TSDT)}

The design tool used in this study is based on a modified TRNSYS component Type 45 linked with other new components and modelled in TRNSYS to evaluate the thermal performance of thermosyphon systems, and uses the genetic algorithm routine for the optimization. Two new components were added to the TRNSYS component Type 45 to account theoretically for the information that would otherwise have to be determined experimentally (namely, $F_{R} \tau \alpha, F_{R} U_{L}, b_{o}, U 1, U 2, U A_{t}$, where all terms are defined in the Nomenclature). The new components and the combined model which is named "Modified TRNSYS Model" have been validated and satisfactory results have been obtained $[23,24]$. The optimization problem is defined as a multi-objective problem consisting of three objective functions: the cost of material contained in the system, the system performance (solar fraction in this case), and the average outlet temperature to the load. However, the problem can simply be treated as a constrained single optimization problem where the cost function is chosen as the objective, and the other two objectives are treated as constraints. Then the problem can be stated as:

Minimise $\quad \cos t(\vec{x})$

Subject to:

$$
\begin{aligned}
& S F(\vec{x}) \geq \varepsilon_{1} \\
& T_{\text {use }}(\vec{x}) \geq \varepsilon_{2}
\end{aligned}
$$

Where $\vec{x}=\left[x_{1}, x_{2}, \ldots, x_{n}\right]^{T}$ is the vector of the $\mathrm{n}$ design variables of the system that are to be optimized and each variable $x_{i}$ is bounded by lower and upper limits $\left[x_{i}^{L}, x_{i}^{U}\right], \varepsilon_{1}$ and $\varepsilon_{2}$ are lower bounds of the constraints that can be varied to find multiple points on the Pareto-optimal front.

Due to the lower demand for hot water in summer and spring seasons in Libya, and to the clear sky as well as to the high solar irradiance, the yearly solar fraction might not be the best choice. Therefore, the calculation of solar fraction is considered only for the winter and autumn seasons (for exactly seven months, from October to April).

The system design parameters considered for optimization in this study are 13 parameters as listed in Table 1 . The riser, header and connecting pipes diameters are not included amongst the optimized parameters. These parameters are instead considered to be fixed information inputs according to pipe standard sizes. The values of these parameters are considered in this study to be $D_{r}=0.008 \mathrm{~m}$ and $D_{h}=D_{p}=0.081 \mathrm{~m}$ respectively. The general configurations of thermosyphon solar water heaters found in practice are depicted in Figure 1. Both of these configurations have been considered in the optimisation process. 


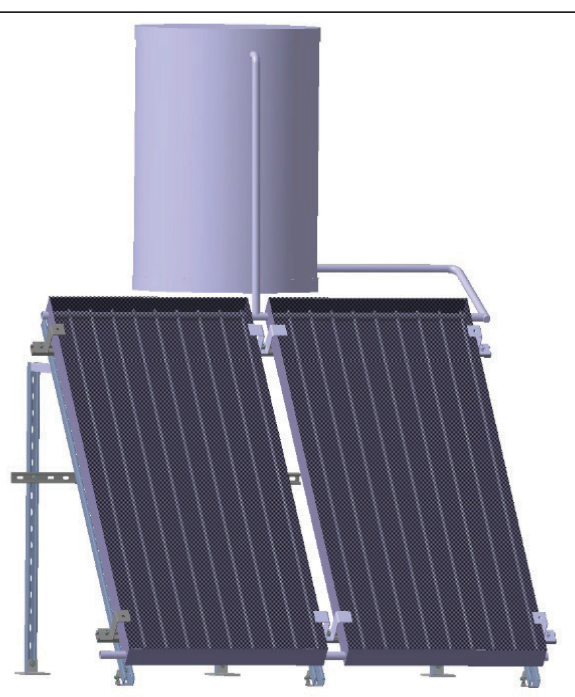

A: Vertical storage tank

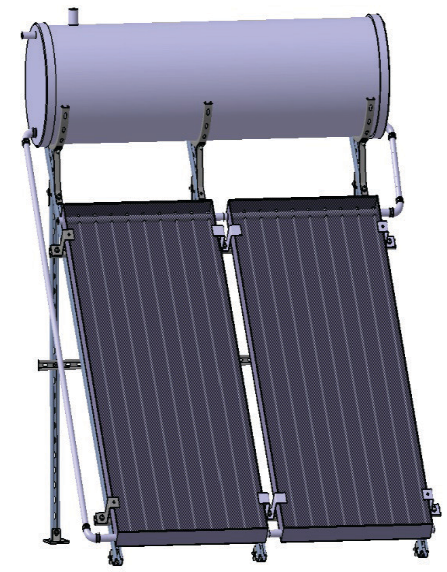

B: Horizontal storage tank

Figure (1). The general view of thermosyphon solar water heaters

Table (1). Design variables of thermosyphon system

\begin{tabular}{lllcc}
\hline & Abbr & \multicolumn{1}{c}{ Stand for } & Limits & increment \\
\hline 1 & Ac & Collector Gross area $\left(\mathrm{m}^{2}\right)$ & {$[1,2.2]$} & 0.025 \\
2 & $\frac{L_{C}}{W_{C}}$ & Collector aspect ratio & {$[0.5,2]$} & 0.02 \\
3 & $\mathrm{Nc}$ & Number of collectors & {$[1,2]$} & 1 \\
4 & $\mathrm{~W}$ & Fin width $(\mathrm{cm})$ & {$[9,20]$} & 0.5 \\
5 & $\mathrm{~L}_{\text {gap }}$ & Gap between cover and absorber plate $(\mathrm{cm})$ & {$[1.5,10]$} & 0.4 \\
6 & $\mathrm{~L}_{\text {inb }}$ & Collector back insulation thickness $(\mathrm{cm})$ & {$[2,5]$} & 0.2 \\
7 & $\mathrm{~L}_{\text {ins }}$ & Collector sides insulation thickness $(\mathrm{m})$ & {$[1,4]$} & 0.2 \\
8 & $\mathrm{~V}_{\mathrm{t}}$ & Tank volume (m $\left.{ }^{3}\right)$ & {$\left[0.4^{*} \mathrm{Q}_{\text {Load }} 1.5^{*} \mathrm{Q}_{\text {Load }}\right]$} & 0.005 \\
9 & $\frac{H}{t}_{D_{t}}$ & Tank aspect ratio & {$[1,3.2]$} & 0.1 \\
10 & $\mathrm{~L}_{\text {tins }}$ & Tank sides insulation thickness $(\mathrm{cm})$ & {$[2,5]$} & 0.2 \\
11 & $\mathrm{~L}_{\text {tint }}$ & Tank top and bottom insulation thickness $(\mathrm{cm})$ & {$[2,5]$} & 0.2 \\
12 & $\mathrm{P}_{\text {aux }}$ & Auxiliary heater power $(\mathrm{kJ} / \mathrm{hr})$ & {$[8,16]$} & 0.2 \\
13 & $\mathrm{~T}_{\text {set }}$ & Auxiliary heater setting temperature $\left({ }^{\circ} \mathrm{C}\right)$ & {$\left[\mathrm{T}_{\text {Load }}-5, \mathrm{~T}_{\text {Load }}+5\right]$} & 0.2 \\
\hline
\end{tabular}

\section{RUNNING THE DESIGN TOOL}

The design tool consists of two main parts: The thermal performance model of thermosyphon solar water heater built in TRNSYS, and the optimisation routine using genetic algorithm built in Intel Visual Fortran 9. The two programs are connected together as illustrated graphically in Figure 2. 


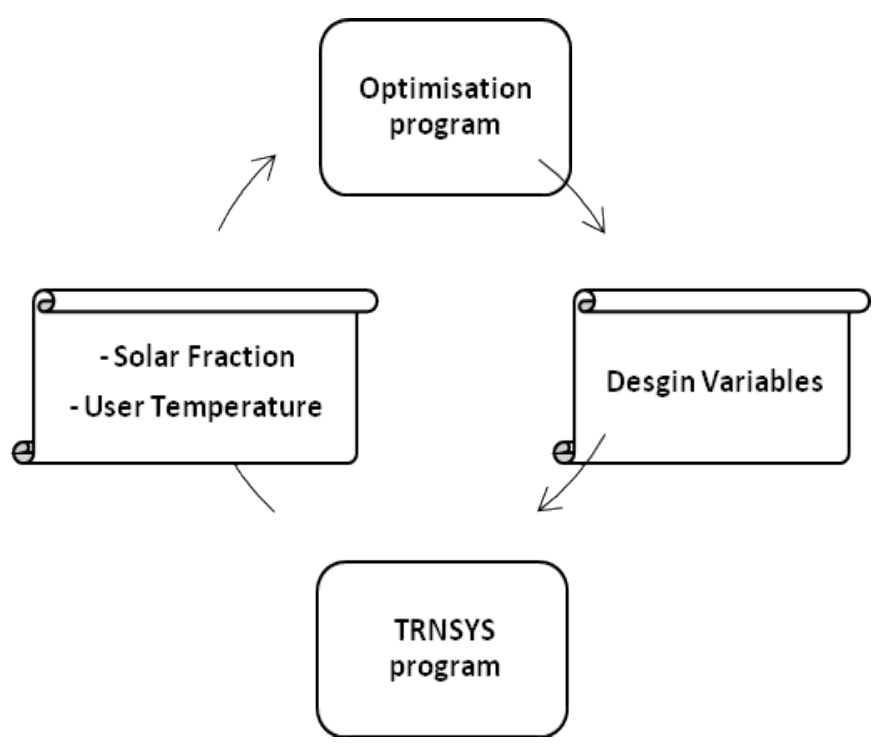

Figure (2). The flow chart of the thermosyphon system design tool

\section{RESULTS AND DISCUSSION}

The design tool can be implemented to obtain the optimum thermosyphon solar water heating system to suit a variety of households, conditions and geographic locations. As a case study, the design tool is applied according to the weather and operating conditions of Tripoli, Libya. A simple, but representative, hot water load pattern as depicted in Figure 3 is used. The thermosyphon system materials used and their optical and thermal properties as considered in this study are shown in Table 2 and Table 3.

Table (2). System materials and their thermal properties

\begin{tabular}{lcc}
\hline \multicolumn{1}{c}{ Part } & Material & Thermal conductivity W/m.K \\
\hline Fin and tube & Copper & 380 \\
Collector insulation & Mineral wool & 0.045 \\
Connecting pipes & Copper & 380 \\
Pipe insulation & Armaflex & 0.036 \\
Tank material & Carbon steel & 50 \\
Tank insulation & Polyurethane & 0.026 \\
\hline
\end{tabular}

Table (3). The solar optical properties of the absorber and the cover plates

\begin{tabular}{ccc}
\hline Part & Properties & Value \\
\hline \multirow{2}{*}{ Absorber } & Absorptivity & 0.95 \\
& Emissivity & 0.05 \\
\multirow{2}{*}{ Cover } & Transmissivity & 0.905 \\
& Emissivity & 0.8 \\
\hline
\end{tabular}

The material prices required by the design tool are given in Table 4 which are based on Libyan free market values in the year 2008 (they are not taken from the manufacturer). 
Table (4). Solar system material and prices

\begin{tabular}{|c|c|c|}
\hline No & Material & Prices $(£ / \mathrm{kg})$ \\
\hline 1 & Copper & 6.9 \\
\hline 2 & Carbon steel & 1.41 \\
\hline 3 & Tempered Glass & 1.2 \\
\hline 4 & Mineral wool & $1.89(40 \mathrm{~kg} / \mathrm{m} 3)$ \\
\hline 5 & Polyurethane foam & $3.27(32 \mathrm{Kg} / \mathrm{m} 3)$ \\
\hline
\end{tabular}

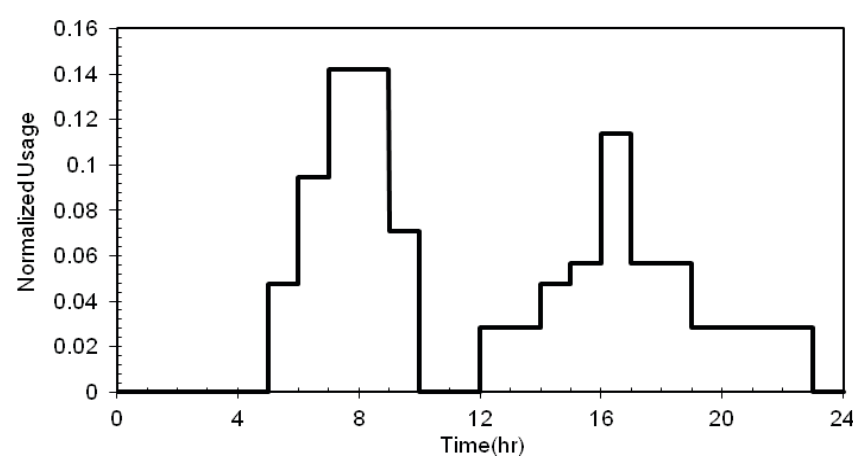

Figure (3). Hot water load pattern used for the study

\section{Optimum Systems}

The design tool is implemented to find the optimum system design that can provide the household with 180 litres of daily hot water at a temperature of $60^{\circ} \mathrm{C}$ for different solar fraction values. This is depicted as 'System A'. The results of 64 simulation runs are shown in Figure 4 and corresponding design parameter values are given in Table 5. Figure 4 represents the trade-off curve between the material cost of the system and the solar fraction of the system in which the grey circular points represent feasible solutions set (dominated solution), and the solid line and white circular points represent the Pareto optimal set ( non-dominated solution). The feasible solution set is the set of all solutions that do not violate the constraints, whereas the Pareto optimal set is the non-dominated subset of the feasible set.

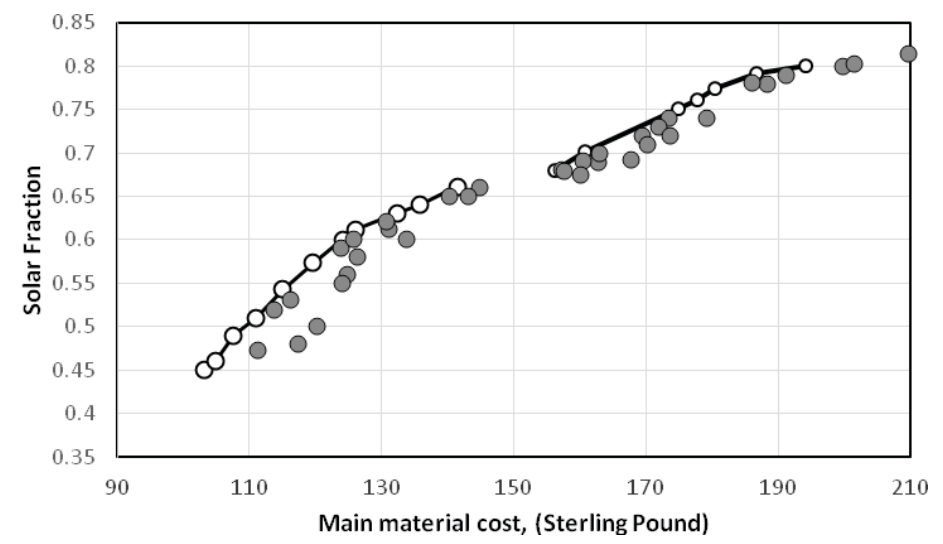

Figure (4). The trade-off between the cost and solar fraction (system A)

The optimum system design that can provide 240 litres of daily hot water at a load temperature of about $60^{\circ} \mathrm{C}$ is sought. This is depicted as 'System B'. The results obtained for the optimum design of the 
thermosyphon system for 240 litres is shown in Figure 5, where 48 resulting points were used to construct the graph.

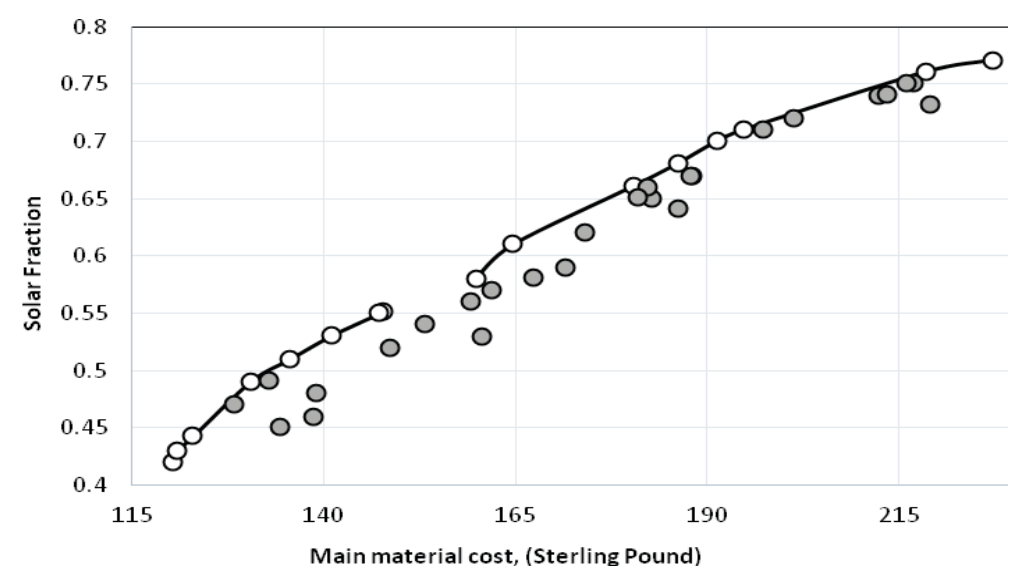

Figure (5). The trade-off between the cost and solar fraction of System B

Figure 6 shows that the shape of the Pareto optimal set of System A and System B have nearly the same trend. This is expected because of the weather condition, load pattern, and the fact that the temperature to the load is the same. The only difference is the amount of daily hot water withdrawn from the system which obviously requires a bigger system size.

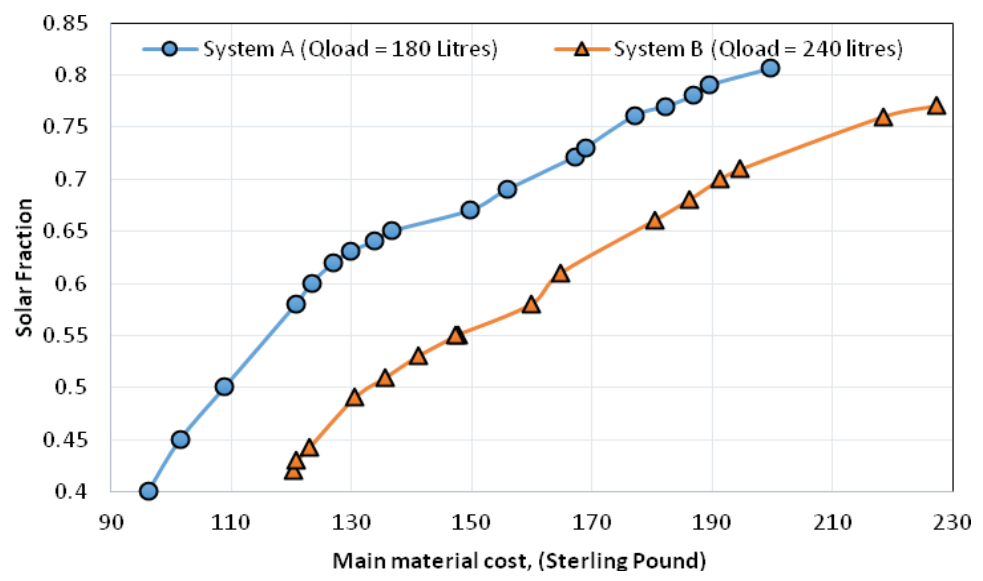

Figure (6). Pareto optimal fronts of System A and System B

\section{Vertical and Horizontal Tanks}

The previous results only examined the optimality of vertical tank systems (as depicted in Figure 1a) for providing 180 litres of hot water at $60^{\circ} \mathrm{C}$. However, in this section, the optimum design of a thermosyphon system (System D) with a horizontal tank is sought (as depicted in Figure 1b). The trade-off curve between the solar fraction and the system cost from 50 simulation runs is shown in Figure 7. Some of the design points on the Pareto optimal set are given in Table 6. Thermosyphon solar water heaters with horizontal tanks are very popular and have a better appearance than vertical tank systems and are relatively easier to be fitted to tilted roofs. 
A comparison between vertical and horizontal tank systems is shown in Figure 8. It is clear from the comparison that vertical tank systems outperform horizontal tank systems for the same system prices, and therefore, wherever possible, it is advisable to use vertical tank systems rather than horizontal tank systems, despite aesthetic appearance.

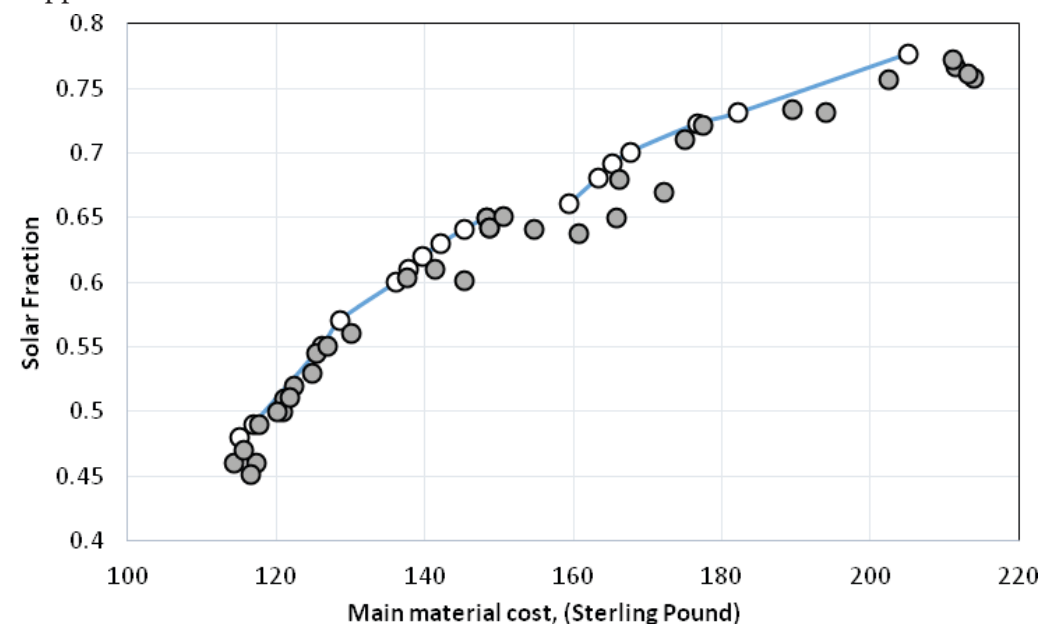

Figure (7). Trade-off curves for an optimum horizontal tank thermosyphon system D

Table (5) Some system design parameters at different solar fraction (System A)

\begin{tabular}{lllllll} 
Generation no & 998 & 1000 & 1000 & 1000 & 1000 & 973 \\
Cost & 101.5 & 108.95 & 123.4 & 136.6 & 158.8 & 177.2 \\
$\mathrm{SF}$ & 0.450 & 0.500 & 0.600 & 0.650 & 0.700 & 0.761 \\
$\left.\mathrm{~T}_{\text {load }}{ }^{\circ} \mathrm{C}\right)$ & 59.71 & 59.71 & 59.71 & 59.70 & 59.71 & 59.70 \\
$\mathrm{Ac}\left(\mathrm{m}^{2}\right)$ & 1.610 & 2.010 & 2.162 & 2.200 & 1.457 & 1.700 \\
$\mathrm{Vt}\left(\mathrm{m}^{3}\right)$ & 0.133 & 0.133 & 0.133 & 0.154 & 0.186 & 0.215 \\
$\mathrm{Ht} / \mathrm{Dt}$ & 1.071 & 1.071 & 1.000 & 1.284 & 1.284 & 1.568 \\
$\mathrm{~W}(\mathrm{~m})$ & 0.146 & 0.198 & 0.147 & 0.120 & 0.152 & 0.188 \\
$\mathrm{Nr}$ & 8 & 5 & 8 & 11 & 6 & 6 \\
Lgap $(\mathrm{m})$ & 0.015 & 0.015 & 0.015 & 0.015 & 0.015 & 0.015 \\
$\mathrm{Paux}(\mathrm{kJ} / \mathrm{h})$ & 11937 & 14476 & 9143 & 12317 & 13079 & 14984 \\
$\mathrm{~L} / \mathrm{W}$ & 1.067 & 1.823 & 1.409 & 1.161 & 1.551 & 1.209 \\
$\mathrm{Noc}$ & 1 & 1 & 1 & 1 & 2 & 2 \\
Linb $(\mathrm{m})$ & 0.028 & 0.022 & 0.036 & 0.036 & 0.024 & 0.026 \\
Lins $(\mathrm{m})$ & 0.010 & 0.010 & 0.012 & 0.018 & 0.010 & 0.010 \\
Ltin $(\mathrm{m})$ & 0.037 & 0.0360 & 0.0400 & 0.040 & 0.044 & 0.048 \\
Ltinb $(\mathrm{m})$ & 0.040 & 0.0380 & 0.0380 & 0.048 & 0.042 & 0.046 \\
Tset $\left({ }^{\circ} \mathrm{C}\right)$ & 64 & 64 & 64 & 64 & 64 & 64 \\
\hline
\end{tabular}


Table (6). Some system design parameters at different solar fraction (Horizontal System)

\begin{tabular}{|c|c|c|c|c|c|c|}
\hline Generation no & 1000 & 1000 & 991 & 1000 & 1000 & 1000 \\
\hline Cost $(£)$ & 112.6 & 122.5 & 140.4 & 161.8 & 188.2 & 244.3 \\
\hline SF & 0.450 & 0.500 & 0.601 & 0.650 & 0.700 & 0.850 \\
\hline Tload $\left({ }^{\circ} \mathrm{C}\right)$ & 59.05 & 59.03 & 59.05 & 59.02 & 59.06 & 59.10 \\
\hline $\mathrm{Ac}\left(\mathrm{m}^{2}\right)$ & 1.590 & 1.743 & 2.162 & 2.200 & 1.542 & 2.123 \\
\hline $\mathrm{Vt}\left(\mathrm{m}^{3}\right)$ & 0.096 & 0.117 & 0.105 & 0.137 & 0.122 & 0.159 \\
\hline $\mathrm{Ht} / \mathrm{Dt}$ & 2.419 & 2.348 & 2.632 & 1.142 & 2.348 & 2.703 \\
\hline $\mathrm{W}(\mathrm{m})$ & 0.117 & 0.119 & 0.124 & 0.090 & 0.125 & 0.125 \\
\hline $\mathrm{Nr}$ & 12 & 13 & 15 & 20 & 13 & 16 \\
\hline Lgap (m) & 0.022 & 0.022 & 0.022 & 0.030 & 0.022 & 0.022 \\
\hline Paux (kJ/hr) & 12825 & 15492 & 8381 & 15619 & 8254 & 13714 \\
\hline $\mathrm{L} / \mathrm{W}$ & 0.736 & 0.677 & 0.583 & 0.642 & 0.547 & 0.500 \\
\hline Noc & 1 & 1 & 1 & 1 & 2 & 2 \\
\hline $\operatorname{Linb}(m)$ & 0.021 & 0.0200 & 0.0253 & 0.031 & 0.020 & 0.020 \\
\hline Lins (m) & 0.010 & 0.0100 & 0.010 & 0.013 & 0.010 & 0.010 \\
\hline Ltin (m) & 0.040 & 0.0400 & 0.040 & 0.040 & 0.040 & 0.040 \\
\hline Ltinb (m) & 0.040 & 0.0360 & 0.039 & 0.040 & 0.036 & 0.040 \\
\hline Tset $\left({ }^{\circ} \mathrm{C}\right)$ & 64 & 62 & 64 & 61 & 62 & 61 \\
\hline
\end{tabular}

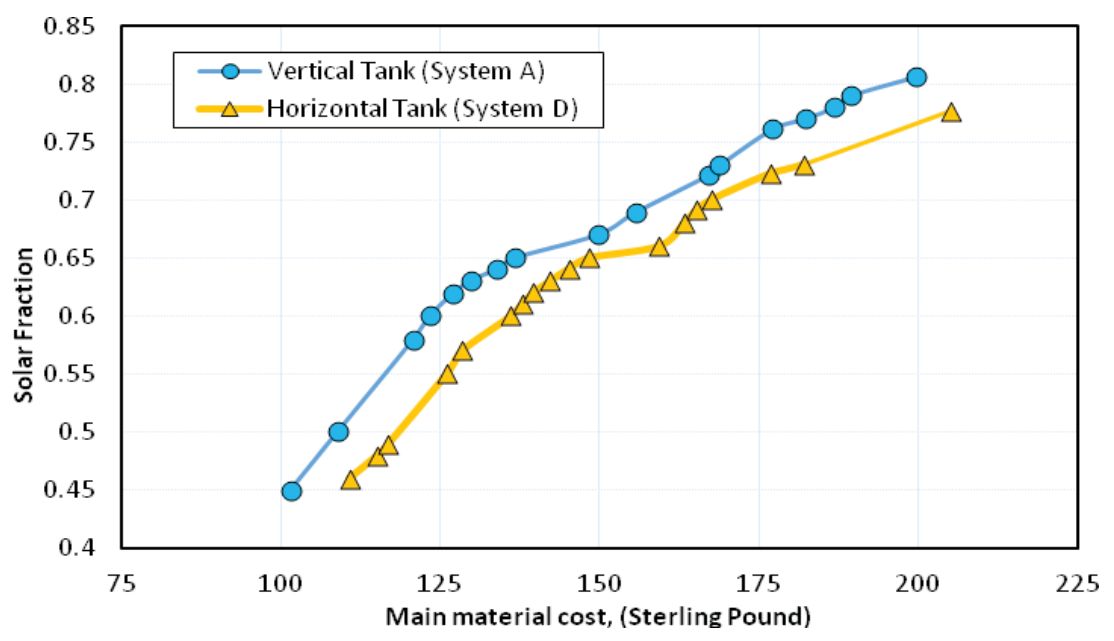

Figure (8). Pareto optimal fronts of vertical and horizontal tank systems

\section{CONCLUSIONS}

The purpose of the study was to develop an optimization routine (optimizer) to be used for the purpose of finding the optimum design parameters of thermosyphon systems. The genetic algorithm optimization procedure was adopted in this study for this purpose because of its ability to optimize multiple parameters simultaneously.

This was then combined with the modified TRNSYS model to constitute the final design tool. Finally, 
the design tool was implemented to find the optimum thermosyphon system for the Libyan environment for different criteria. The conclusions are as follows.

i) The design tool produced is capable of delivering the optimum thermosyphon system design that fits a particular situation and purpose. This, in turn, eliminates the unnecessary cost resulting from the oversizing of systems.

ii) The design tool has shown the difference in cost and performance of vertical versus horizontal tank systems designed for the same purpose. For the case tested, it is better to have a vertical tank than a horizontal one.

iii) The study has extended the TRNSYS library by adding two new components: Type 210 (collector characteristic component), and Type 211 (pipe-tank heat loss coefficients component).

iv) The design tool developed offers a potentially very promising means for sizing thermosyphon solar water heating systems and has potential to be developed commercially for this purpose, subject to further successful validation.

\section{NOMENCLATURE}

\begin{tabular}{|c|c|}
\hline Ac Collector area $\mathrm{m}^{2}$ & Nr Number of risers \\
\hline Dp Inlet and outlet connecting pipes diameter (m) & $\mathrm{P}_{\text {aux }}$ Auxiliary energy input to tank $(\mathrm{kJ} / \mathrm{hr})$ \\
\hline Dr Riser diameter $(\mathrm{m})$ & $\mathrm{Q}_{\text {load }}$ Hot water demand (Lit) \\
\hline Dt Tank diameter $(\mathrm{m})$ & $\mathrm{T}_{\text {set }} \quad$ Auxiliary heater setting temp $\left({ }^{\circ} \mathrm{C}\right)$ \\
\hline$F_{R} \tau \alpha$ Intercept of the collector efficiency curve & $\mathrm{T}_{\text {load }}$ User hot water temperature $\left({ }^{\circ} \mathrm{C}\right)$ \\
\hline$F_{R} U_{L}$ Slope of the collector efficiency curve $\left(\mathrm{kJ} / \mathrm{hr} \mathrm{m}^{2}{ }^{\circ} \mathrm{C}\right)$ & SF Solar fraction \\
\hline $\mathrm{L}_{\text {gap }}$ The height between the absorber and the cover & $U A_{t}$ Overall $U A$ value for tank $\left(\mathrm{kJ} / \mathrm{hr}{ }^{\circ} \mathrm{C}\right)$ \\
\hline plates (m). & U1, U2 Loss coefficients for inlet and outlet \\
\hline $\mathrm{L}_{\text {inb }}$ Collector back insulation thickness $(\mathrm{m})$ & pipes $\left(\mathrm{kJ} / \mathrm{hr} \mathrm{m}^{2 \circ} \mathrm{C}\right)$ \\
\hline $\mathrm{L}_{\text {ins }}$ Collector sides insulation thickness (m) & Vt Tank volume (Lit) \\
\hline $\mathrm{L}_{\text {tins }}$ Tank insulation side thickness $(\mathrm{m})$ & Wc Collector Width (m) \\
\hline $\mathrm{L}_{\text {tint }}$ Top tank insulation thickness $(\mathrm{m})$ & W Fin width $(\mathrm{cm})$ \\
\hline \multicolumn{2}{|l|}{ Ht Tank height (m) } \\
\hline Noc Number of collectors & \\
\hline
\end{tabular}

\section{REFERENCES}

[1]. Morrison, G. L. and J. E. Braun, 1985. System Modelling and Operation characteristics of thermosyphon solar water heaters. Solar Energy, 34, 389-405.

[2]. Shariah, A., Shalabi, B., 1997. Optimal design for a thermosyphon solar water heater. Renewable Energy, 11 (3), 351-361.

[3]. Shariah, A. M., Douglas, C. Hittle and Lof, G.O.G, 1994. Computer simulation and optimization of design parameters for thermosyphon solar water heater. In Proc. Joint solar Engineering Conference ASME, pp 393-399.

[4]. Hasan A., 1997. Thermosyphon solar water heaters: effect of storage tank volume and configuration on efficiency. Energy 
Conversion and Management, 38 (9), 847-854.

[5]. Barley CD, Winn CB, 1978. Optimal sizing of solar collector by the method of relative areas. Solar Energy, 21, $279-289$.

[6]. Chang KK, Minardi A., 1980. An optimisation formulation for solar heating systems. Solar Energy, 24, 99-103.

[7]. Kulkarni GN, Kedare SB, Bandyopadhyay S., 2007. Determination of design space and optimisation of solar water heating systems. Solar Energy, 81, 958-968.

[8]. Michelson E., 1982. Multivariate optimisation of a solar water heating system using SIMPLEX method. Solar Energy, 29 (2), 89-99, 1982.

[9]. Pedersen PV., 1993. System design optimisation for large building integrated solar heating system for domestic hot water. Solar Energy, 50 (3), 267-273.

[10]. Gupta, C. L. and H. P. Garg, 1968. System design in solar water heaters with natural circulation. Solar Energy, 12, 163182 .

[11]. Norton B.m Probert, S.D, 1983. Optimising the design of natural-circulation solar-energy water heaters. In Proc. Passive and Low Energy Architecture, pp 587-596.

[12]. Malkin, M. P., Klein, S. A.; Duffie, J. A., Copsey, A. B., 1987. Design methods for thermosyphon solar domestic hot water systems. Journal of Solar Energy Engineering, Transactions of the ASME, 109 (2), 150-155.

[13]. Shariah, A.M. and G. O. G. Löf, 1996. The optimization of tank-volume-to-collector-area ratio for a thermosyphon solar water heater. Renewable Energy, 7 (3), 289-300.

[14]. Longsheng Lu, Xiaowu Wang, Shuai Wang, Xiaokang Liu, 2017. Optimal Structure Design of a Thermosyphon Solar Water Heating System with Thermal and Dynamic Models. Heat Transfer Engineering, DOI: 10.1080/01457632.2017.1379347

[15]. Cardemila Jose M, Starke Allan R, Colle Sergio, 2018. Multi-objective optimization for reducing the auxiliary electric energy peak in low cost solar domestic hot-water heating systems in Brazil. Solar Energy 163, 486-496.

[16]. Mamouri Sina Jahangiri, Bénard André, 2018. New design approach and implementation of solar water heaters: A case study in Michigan. Solar Energy 162, 165-177.

[17]. Loomans, M., Visser, H., 2002. Application of the genetic algorithm for optimisation of large solar hot water systems. Solar Energy 72 (5), 427- 439

[18]. Hin, Jason Ng Cheng, and R. Zmeureanu, 2014, Optimization of a residential solar combisystem for minimum life cycle cost, energy use and exergy destroyed, Solar Energy, 100, pp 102-113

[19]. Rey A., and Zmeureanu R., 2016. Multi-objective optimization of a residential solar thermal combisystem. Solar Energy 139, 622-632.

[20]. Shrivastava R.L., Kumar V., Untawale S.P., 2017. Modelling and simulation of solar water heater: A TRNSYS perspective. Renewable and Sustainable Energy Reviews 67, 126-143.

[21]. Nhut Le Minh, Park Y. C., 2013. A study on automatic optimal operation of a pump for solar domestic hot water system. Solar Energy 98, 448-457.

[22]. Abdunnabi M., 2012. Optimum Values of Tank Volume to Collector Area Ratios of Thermosyphon Solar Water Heaters for Libyan Families. Journal of Solar Energy and Sustainable Development, JSESD, 1 (1), 25-31.

[23]. Abdunnabi M. and Loveday, DL, 2012. Optimisation of Thermosyphon Solar Water Heaters Using TRNSYS. Part1: Improved Model Development and Validation, IPCBEE conference, Singapore, 26-28, pp 145- 153.

[24]. Abdunnabi, M., 2009. Design Tool for Sizing and Optimizing Thermosyphon Solar Water Heaters. PhD Thesis, Loughborough University, UK. 